\title{
Infliximab for Early Endoscopic Recurrence in Patients with Crohn's Disease
}

\author{
Takayuki Yamamoto
}

Received: 18 February 2012/ Accepted: 29 February 2012/Published online: 24 March 2012

(C) Springer Science+Business Media, LLC 2012

To the Editor,

I read with great interest the recent article by Sorrentino et al. [1]. In their prospective study, patients with endoscopic recurrence (Rutgeerts score [2] $\geq 2$ ) at 6 months after resection were treated with infliximab or mesalamine. At week 54, infliximab significantly improved endoscopic lesions including $54 \%$ with endoscopic remission. In contrast, none of the patients treated with mesalamine achieved endoscopic remission. We have previously reported similar results [3]. During 6-month treatment, endoscopic lesions (Rutgeerts score [2] $\geq 2$ at 6 months after resection) were improved in $75 \%$ of patients (including $38 \%$ with complete mucosal healing) treated with infliximab versus none of the patients treated with mesalamine. In both studies [1, 3], infliximab significantly reduced clinical recurrence. From these results, infliximab appears to improve endoscopic lesions observed 6 months after surgery and reduce the incidence of clinical recurrence.

There are a number of risk factors for recurrence after surgery for Crohn's disease (CD), including smoking and perforating disease [4]. Although these factors can be recognized at the time of surgery, it is not easy to assess the precise risk of postoperative recurrence in an individual patient. Furthermore, these parameters are of limited use to identify patients at high risk of recurrence and to establish prophylactic strategy for postoperative recurrence. In contrast, the severity of endoscopic inflammation in the early postoperative period is a reliable risk factor for recurrence [2]. Patients with severe endoscopic lesions develop early clinical recurrence. In contrast, patients with

T. Yamamoto $(\bowtie)$

Inflammatory Bowel Disease Center, Yokkaichi Social Insurance Hospital, 10-8 Hazuyamacho, Yokkaichi, Mie 510-0016, Japan e-mail: nao-taka@sannet.ne.jp no or very mild lesions have an uneventful postoperative clinical course.

A randomized controlled trial (RCT) found that infliximab therapy initiated soon after surgery was useful for preventing recurrence [5]. However, this new agent cannot be recommended for all patients after surgery because of potential serious adverse events and high medical costs. It should be used for patients at high risk of recurrence. Patients with early endoscopic lesions are good candidates for infliximab therapy after surgery for $\mathrm{CD}$. The results of the study by Sorrentino et al. [1] and our previous trial [3] support the use of infliximab for early postoperative CD recurrence. However, RCTs with a larger number of patients and a longer follow-up period are necessary to more accurately evaluate the efficacy of infliximab for early endoscopic lesions after surgery for CD.

Conflict of interest None to declare.

\section{References}

1. Sorrentino D, Terrosu G, Paviotti A, et al. Early diagnosis and treatment of postoperative endoscopic recurrence of Crohn's disease: partial benefit by infliximab-a pilot study. Dig Dis Sci. 2012. (Epub ahead of print). doi:10.1007/s10620-011-2025-z.

2. Rutgeerts P, Geboes K, Vantrappen G, et al. Predictability of the postoperative course of Crohn's disease. Gastroenterology. 1990; 99:956-963.

3. Yamamoto T, Umegae S, Matsumoto K. Impact of infliximab therapy after early endoscopic recurrence following ileocolonic resection of Crohn's disease: a prospective pilot study. Inflamm Bowel Dis. 2009;15:1460-1466.

4. Yamamoto T. Factors affecting recurrence after surgery for Crohn's disease. World J Gastroenterol. 2005;11:3971-3979.

5. Regueiro M, Schraut W, Baidoo L, et al. Infliximab prevents Crohn's disease recurrence after ileal resection. Gastroenterology. 2009;136:441-450. 